\title{
PROFITABILITY, PRODUCT MARKET COMPETITION, AND STOCK RETURNS
}

\section{SCOTT LI}

California State University, Los Angeles

* Corresponding Author: Scott Li, PhD, MPA, Assistant Professor of Finance, College of Business and Economics, California State University, Los Angeles $₫ \underline{\text { sli86@calstatela.edu }}$

\begin{abstract}
This paper finds that product market competition level (measured by Herfindahl Hirschman Index using Fama French 48 industries) affects the performance of zero-cost investment strategies based on gross probability. From 1973 to 2017, the positive returns from such strategy mainly comes from the most competitive industry quintile while a strong reversal exists the second most competitive quintile. The same strategy does not generate any statistically significant returns in concentrated industry quintiles. Out of 25 dependently sorted portfolios on product market competition level and gross profitability, the top performing portfolio comes from the least profitable firms in the second most competitive industry quintile, where $65 \%$ of firms are from pharmaceutical and oil industries.
\end{abstract}

Keywords: Fama French, investment strategies, markets, stocks

\section{Introduction}

Sir John Templeton (1912-2008) is regarded by Money Magazine as "arguably the greatest global stock picker of the century" in 1999. During a one-on-one interview with Tony Robbins on investing, he mentioned that one of the criteria he used to pick stocks was to buy firms with higher profitability compared to its direct competitors. There are two factors to this measure: profitability and product market competition. In a very competitive industry where many firms are competing for the same market, higher profitability demonstrates superior productivity and efficiency. However, if a firm resides in a highly concentrated industry where it possesses strong market power and majority market share, profitability becomes less comparable especially for industries that are monopolies. It also does not make much sense to compare two firms' profitability when they are from totally unrelated industries that have drastically different operation characteristics and cost structures. In other words, profitability, as a performance measure, is better used in a more comparable environment. Inspired by Sir John Templeton's stock picking criteria, the purpose of this paper is to test a zero-investment strategy that long stocks with the highest scaled profitability and short the ones with the lowest after controlling product market competition levels. This way firms are compared

\footnotetext{
1 The video clip of the interview is part of Tony Robbins' Ultimate Edge Program
} 
with their direct competitors in the same industry, and other industries that have similar product market competition levels.

In academia, on the one hand, there are many studies documenting the relationship between profitability and stock returns. Haugen and Baker (1996) and Cohen, Gompers, and Vuolteenaho (2002) find that firms with higher probabilities are associated with higher average stock returns. Fama and French (2008) find that, however, profitability produces a mixed picture, where higher positive profitability seems to be associated with higher abnormal returns, but there is no evidence that negative profitability leads to low abnormal return from 1963 to 2005. In their Table II (p.1660), it shows that only the small (versus micro and big) stock group generates positive high-minus-low (HML hereafter) value weighted returns with statistical significance $(0.79 \%$ per month with a t-statistic of 2.87). Novy-Marx (2013) claims that profitability, measured by gross profits-to-asset ratio has roughly the same predicting power as book-to-market ratio (BM hereafter) in cross section of stock returns. His results in Table 6 (p.10) show that across all BM quintiles, the profitability HML raw returns are all positive and statistically significant, although the abnormal returns from Fama French three-factor regression are significant only in the $1^{\text {st }}, 2^{\text {nd }}$, and $4^{\text {th }} \mathrm{BM}$ quintiles. Fama and French (2015) construct a five-factor model, adding profitability and investment factor to the existing three. Such model improved the explanatory power of their three-factor model (Fama and French, 1993), although they use operating profitability ${ }^{2}$ instead of gross profitability to construct the new factor. At the same time, Ball at el. (2015) construct an alternative operating profitability measure ${ }^{3}$ and claim that their measure displays a stronger link with stock returns than gross profit. Subsequently, Ball at el. (2016) use cash-based profitability measures and show that it subsumes predicting power of cross section of average returns by their previously used accruals based operating profitability measure. While scholars examine and argue the superiority of alternative profitability measure over others, it is reasonable to say that gross profitability is the cleanest measure, and it can be used to compare firms across industries because different industries have different cost structures by nature. I use scaled gross profit by book value of total assets to measure firm's profitability to form portfolios.

On the other hand, there are a few studies examining the relationship between product market competition level and stock returns with mixed results. For example, Hou and Robinson (2006) find that industry concentration level (measured by Herfindahl Hirschman Index using three-digit SIC code) is negatively related with stock returns from 1963 to 2001 . Their study supports the creative destruction theory by Schumpeter (1912), which states that firms in competitive industries have more incentives to engage in innovation activities and are thus more likely to have higher future stock returns. However, their findings are challenged by Grullon et al. (2019), who show that during the last two decades, about $75 \%$ of industries (using three-digit NAICS ${ }^{4}$ code) have become more and more concentrated. At the same time, firms in those concentrated industries display higher profits and stock returns. The difference is likely caused by using different sample periods because market structure evolves over time. It is also important

\footnotetext{
2 Operating profitability equals revenue minus cost of goods sold, interest expense, and SG\&A expenses, and then divided by book equity (p.4). All accounting information is based fiscal year ending in $t-1$.

3 Their deflated operating profitability equals gross profit minus SG\&A expenses (excluding research and development expenditure) and then divided the book value of total assets (p.240).

4 North America Industry Classification System (NAICS) was adopted in 1997 to replace Standard Industry Classification (SIC) code. Both NAICS and SIC codes are available in Compustat, while CRSP contains SIC code only. The SIC codes have substantial discrepancy between CRSP and Compustat database, documented by Kahle and Walking (1996).
} 
to point out that these two studies use completely different industry classification systems.

This paper brings these two dimensions together and find that a value-weighted zeroinvestment strategy that longs stocks with high profitability and shorts the ones with low profitability works well only in the most competitive industries. More importantly, there seems to be a strong reversal in the second most competitive industry quintile, which is prominent during the past two decades. This phenomenon is likely caused by the evolution of market structure and the unique characteristics of industries in that group.

The rest of this paper is structed as follows. Section 2 describes the data and provides the summary of statistics. Section 3 examine the performance of the zero-investment strategy based on product market competition level and scaled gross profitability. Section 4 concludes.

\section{Data and Statistics Summary}

I use publicly held firms listed on the NYSE, AMEX, or NASDAQ from 1973 to 2017 and restrict the sample to firms issuing common shares. The monthly stock return file is from CRSP, and annual firm fundamentals come from Compustat. A firm must have non missing gross profit (GP hereafter), positive market equity (ME), total assets, book equity, and at least twelve consecutive monthly return observations prior to July of year $t$ to be included in the sample of year t. After merging CRSP and Compustat datasets, firms without annual fundamentals are deleted from the sample. Following the common practice in the literature, financial industries (one-digit SIC as 6) are excluded from the sample. This produces 1,567,199 firm observations, with 2902 firms/year on average. I choose 1973 as the start year because it is the year that the inclusion of NASDAQ stocks takes place, although the results are consistent when extended to 1963. The number of firms in the sample continues to rise until it reaches its peak at 3926 in 1997. After that, the number starts to decline sharply. Likewise, the average industry concentration level also declines from 1973 to 1997, and then rises steadily after that. This is consistent with Grullon et al.'s (2019) study for the past two decades.

The scaled GP equals gross profit divided by book value of total assets (GP/AT). Because the unique characteristic of operation and cost structure, industries have different average GP/AT ratio. Among the 44 non-financial Fama French 5 industries, Retail has the highest average GP/AT ratio: 0.69, followed by Soda (0.59), Household (0.57), Clothing (0.54), Smoke (0.50), and Books (0.50). This is a huge contrast to Oil, Mines, Gold, Utility, and Pharmaceutical industry that all have GP/AT below 0.20 as Table 1 shows. It does not make much sense to compare firms' gross profit margins across industries that have very different nature.

I follow Hou and Robinson (2006) and measure the product market competition level (industry concentration level) using the Herfindahl-Hirschman Index (HHI hereafter) based on net sales: 6

$$
H H I_{j, t}=\sum_{i=1}^{I} \text { product market share }{ }_{i, j, t}
$$

\footnotetext{
5 Fama French 48 industry classification is based on four-digit SIC. It can be downloaded from Kenneth French's website: https://mba.tuck.dartmouth.edu/pages/faculty/ken.french/Data_Library/det 48 ind_port.html 6 In the $\mathrm{HHI}$ equation, $i$ stands for individual firm, $j$ is the industry firm $i$ belongs to, $t$ stands for year $t$.
} 
In each fiscal year, as equation (1) shows, the $\mathrm{HHI}$ is generated by calculating the sum of all sales in every industry grouped by Fama French 48 (FF 48 hereafter) industries. I use FF 48 instead of three-digit SIC industries because the latter produces highly concentrated industries that are consisted of mostly small single-firm industries, which take up the top $20 \%$ of all industries. Two-digit SIC industries mitigate such issue; but it still produces a heavily right-skewed distribution where only $3.86 \%$ and $8.32 \%$ of firm observations exist in the most and second-most concentrated industry quintiles. Meanwhile, over half of the sample (54.25\%) are clustered in the most competitive industry quintile. This may not present an accurate description of market structure. In comparison, FF 48 classification produces a much more normalized distribution of firms across all industry quintiles. The market share of each firm in the industry is calculated by division of the firm's sales and industry total sales. I then square the market share of each firm and add all squared shares to compute the $\mathrm{HHI}$ of that industry, a value ranging from 0 to 1 . If $\mathrm{HHI}$ equals 1 , the industry is a monopoly. The bigger $\mathrm{HHI}$ is, the more concentrated the industry is.

\section{Table 1: Average Gross Profitability by Industry 1973-2017}

Note: The average gross profit over total assets ratio (GP/AT) is calculated for each of Fama French $48^{7}$ industries (financial industries excluded) over 1973-2017. The sample includes public held firms with common shares traded on NYSE, AMEX and NASDAQ. A firm must have positive book equity, total assets, non-missing gross profit from Compustat to be included in the sample. For details of Fama French 48 industries please refer to the footnote.

\begin{tabular}{ccc|ccc}
\hline FF IND & \# of Firms & GP/AT & FF IND & \# of Firms & GP/AT \\
\hline RTAIL & 177 & 0.69 & HLTH & 53 & 0.35 \\
SODA & 7 & 0.59 & AUTOS & 54 & 0.34 \\
HSHLD & 66 & 0.57 & TXTLS & 28 & 0.33 \\
CLTHS & 55 & 0.54 & MEALS & 61 & 0.32 \\
SMOKE & 3 & 0.50 & FABPR & 16 & 0.32 \\
BOOKS & 28 & 0.50 & OTHER & 58 & 0.31 \\
TOYS & 30 & 0.49 & GUNS & 7 & 0.30 \\
FOOD & 66 & 0.48 & FUN & 46 & 0.29 \\
COMPS & 120 & 0.47 & BOXES & 12 & 0.28 \\
LABEQ & 80 & 0.47 & AERO & 22 & 0.28 \\
WHLSL & 132 & 0.45 & TELCM & 69 & 0.27 \\
BUSSV & 312 & 0.45 & STEEL & 51 & 0.25 \\
MEDEQ & 102 & 0.43 & SHIPS & 8 & 0.25 \\
PAPER & 53 & 0.42 & TRANS & 75 & 0.25 \\
PERSV & 36 & 0.41 & AGRIC & 10 & 0.24 \\
RUBBR & 38 & 0.40 & CNSTR & 45 & 0.22 \\
BEER & 13 & 0.39 & COAL & 6 & 0.21 \\
CHIPS & 202 & 0.39 & OIL & 141 & 0.19 \\
MACH & 136 & 0.39 & MINES & 14 & 0.16 \\
ELCEQ & 56 & 0.38 & GOLD & 11 & 0.11 \\
CHEM & 67 & 0.38 & UTIL & 92 & 0.11 \\
BLDMT & 87 & 0.37 & DRUGS & 158 & 0.11 \\
\hline
\end{tabular}

7 Fama French 48 industry SIC codes are downloaded from Kenneth French's website: https://mba.tuck.dartmouth.edu/pages/faculty/ken.french/data library.html 
Following Fama and French (1992), at the end of June of year $t$, I form quintile portfolios based on firm's GP/AT ratio from fiscal year ending in year $t-1$, and then hold each quintile portfolio from July of year $t$ to June of year $t+1$ before rebalancing. The summary of average firm characteristics in each profitability quintile is presented in Table 2. It seems that, as profitability increases, the average monthly return increases monotonically from $1.08 \%$ to $1.67 \%$. This supports the findings of previous studies. Accumulative momentum (average monthly returns from month $t-2$ to month $t-12$ ) follows a similar pattern. The smallest average firm size belongs to the most profitable quintile (strong) while the biggest average firm size resides in the second weakest profitability quintile. Book to market ratio follows a similar pattern. Scaled R\&D expenses display a strong U-shape pattern, where the firms with weakest GP/AT ratio having the highest R\&D/AT ratio. However, R\&D expenses is not recorded as part of Cost of Goods Sold (COGS) based on General Accepted Accounting Principles (GAAP), so it should not affect gross profitability. The inverted-U shape pattern of Sales seems to indicate that is no clear correlation between quantity of sales and gross profitability. At last, industry concentration level (HHI) seems to rise as the gross profitability rises, although not monotonically.

\section{Table 2. Firm Level Summary Statistics by Gross Profitability 1973-2017}

Note: This table presents the average firm level statistics from each profitability quintile portfolio. The portfolios are formed at the end of June at calendar year t. Firms are sorted by gross profit to total assets ratio (GP/AT) at the end of June into quintiles. The GP/AT ratio is from the report of last fiscal year ending in year $t-1$. Number of firms is the overall average number of firms per year in each GP/AT quintile from 1973 to 2017. Return (\%) is the average monthly raw return calculated using the variable RET from CRSP dataset. Momentum (\%) is the average monthly raw return of accumulative returns from month $t-2$ to month $t-12$ at the end of June each year. Log (ME) is the natural log of market equity (ME) calculated as the product of absolute value of price (PRC) and shares outstanding (SHROUT) from CRSP dataset. A firm must have positive ME to be included in the sample. BM is book to market ratio. Book equity is calculated from Compustat, market equity used in calculating BM is from December of year $\mathrm{t}-1$. R\&D/AT is scaled research and development expense by total assets. Log (sale) is the natural log of sales. HHI is Herfindahl Hirschman Index. For details on how to calculate HHI, please refer to the description in Section 2.

\begin{tabular}{cccccccccc}
\hline $\begin{array}{c}\text { GP/AT } \\
\text { Rank }\end{array}$ & \# of firms & GP/AT & Return & Momentum & log(ME) & BM & R\&D/AT & log(Sale) & HHI \\
\hline Weak & 580 & 0.024 & 1.082 & 0.910 & 4.760 & 0.593 & 0.078 & 3.167 & 0.072 \\
$\mathbf{2}$ & 580 & 0.232 & 1.186 & 1.149 & 5.100 & 0.612 & 0.018 & 3.411 & 0.080 \\
$\mathbf{3}$ & 580 & 0.349 & 1.348 & 1.388 & 4.917 & 0.556 & 0.029 & 3.252 & 0.084 \\
$\mathbf{4}$ & 580 & 0.482 & 1.459 & 1.637 & 4.872 & 0.504 & 0.042 & 3.171 & 0.085 \\
Strong & 580 & 0.789 & 1.666 & 1.931 & 4.682 & 0.454 & 0.052 & 3.185 & 0.081 \\
\hline
\end{tabular}

\section{Gross Profitability, Product Market Competition and Stock Returns}

Previous studies have demonstrated that gross profitability is positively related to stock returns. A zero-investment strategy that longs stocks with the highest GP and shorts the ones with the lowest can generate positive and statistically significant returns. However, is this pattern consistent across all product market competition levels? To have higher GP than direct competitors demonstrate a firm's superior productivity and efficiency. However, if product market is highly concentrated, especially with one or only a few firms in the game, will profitability still be a relevant indicator to predict future stock returns? Fama and French (2008) find a mixed picture showing that there is lack of evidence that firms with negative profitability leads to lower abnormal returns. I hypothesize that the zero-investment strategy is prominent only in very competitive industries, where higher profitability in comparison with direct competitors can be used as a good signal for investors to pick stocks.

To analyse how product market competition level may affect the performance of the zero-investment strategy based on GP, at the end of June of year $t$, I sort all stocks into 
quintiles based on the industry concentration level (ICL hereafter) of the industry they belong to. With 44 non-financial industries in the sample, it gives us about 9 industries in each quintile. Within each quintile, I further sort the stocks into quintiles based on their GP/AT ratio from the fiscal year ending in year $t-1$. This produces 25 ICL \& GP/AT portfolios. The zero-investment strategy is to long the stocks in the strongest GP/AT quintile and short the ones in the weakest GP/AT quintile, and then hold the Strong Minus Weak (SMW) 8 portfolios for 12 months before rebalancing.

First, without creating sections of stocks based on $\mathrm{ICL}$, using the stock market as whole, the equal weighted SMW strategy generates $0.62 \%$ per month with a t-statistic of 4.92 from 1973-2017. This translates into a return of $7.44 \%$ per year. However, the value weighted SMW strategy generates much lower returns $(0.24 \%$ per month) with no statistical significance during the same period. The comparison indicates that the higher returns of equal weighted SMW strategy may be driven by small stocks in the sample because small stocks outperform big stocks consistently over time. This is also known as the size effect identified by Fama and French (1992).

\section{Table 3. Average Stock Returns of Portfolios by Gross Profitability, and by Gross Profitability \& Industry Concentration Level 1973-2017}

Note: In column "All", at the end of June of year t from 1973 to 2017, all firms are sorted by scaled gross profitability (gross profit/total assets) in quintiles. The zero-investment SMW strategy is to long stocks in the highest (Strong) GP/AT quintile and short the ones in the lowest (Weak) GP/AT quintile, and then held for 12 months from July of year $t$ to June of year $t+1$ before rebalancing. In column from "Low" to "High" as Industry Concentration Level (ICL), at the end of June of year $t$, all firms are sorted (by industry) first by the ICL into quintile. Then, within each ICL quintile, firms are sorted again based on GP/AT into quintiles. This creates $25 \mathrm{ICL}$ \& GP/AT dependently sorted portfolios. Within each ICL quintile, the zero-investment SMW strategy is to long stocks in the highest (Strong) GP/AT quintile and short the ones in the lowest (Weak) GP/AT quintile, and then held for 12 months from July of year $t$ to June of year $t+1$ before rebalancing. The average monthly stock raw returns (\%), both equal weighted and value weighted, are presented in this table. T-statistics calculated with Newey-West adjusted standard errors are presented in parentheses.

\begin{tabular}{|c|c|c|c|c|c|c|c|c|c|c|c|c|c|}
\hline \multicolumn{7}{|c|}{ Equal Weighted Portfolio Returns } & \multicolumn{7}{|c|}{ Value Weighted Portfolio Returns } \\
\hline \multicolumn{7}{|c|}{ Industry Concentration level (FF48) } & \multicolumn{7}{|c|}{ Industry Concentration level (FF48) } \\
\hline GP & All & Low & 2 & 3 & 4 & High & GP & All & Low & 2 & 3 & 4 & High \\
\hline \multirow[b]{2}{*}{ Weak } & 1.14 & 0.96 & 1.38 & 1.10 & 0.89 & 1.07 & \multirow[b]{2}{*}{ Weak } & 1.47 & 1.22 & 2.44 & 1.86 & 1.43 & 1.57 \\
\hline & $(4.01)$ & (3.58) & $(3.13)$ & (3.12) & $(2.29)$ & $(2.88)$ & & (6.98) & $(6.24)$ & $(6.67)$ & $(5.90)$ & $(5.46)$ & (5.46) \\
\hline \multirow[b]{2}{*}{2} & 1.25 & 1.22 & 1.09 & 1.40 & 1.12 & 1.13 & \multirow[b]{2}{*}{2} & 1.49 & 1.48 & 1.53 & 1.84 & 1.68 & 1.37 \\
\hline & $(5.01)$ & $(4.10)$ & (3.51) & $(4.60)$ & (3.72) & (3.72) & & $(7.73)$ & (7.07) & (6.97) & $(7.36)$ & (6.99) & (5.55) \\
\hline \multirow[b]{2}{*}{3} & 1.43 & 1.38 & 1.21 & 1.45 & 1.37 & 1.39 & \multirow[b]{2}{*}{3} & 1.69 & 1.67 & 1.45 & 1.68 & 1.53 & 1.62 \\
\hline & $(5.73)$ & $(4.42)$ & $(4.15)$ & $(4.68)$ & $(4.30)$ & $(4.36)$ & & (7.91) & $(6.69)$ & (7.17) & $(6.23)$ & $(6.96)$ & (6.87) \\
\hline \multirow[b]{2}{*}{4} & 1.54 & 1.42 & 1.48 & 1.45 & 1.36 & 1.58 & \multirow[b]{2}{*}{4} & 1.57 & 1.67 & 1.68 & 1.52 & 1.49 & 1.63 \\
\hline & (6.09) & $(4.49)$ & (5.31) & $(4.59)$ & (4.43) & $(5.26)$ & & (7.69) & $(7.13)$ & (8.33) & $(6.03)$ & (6.43) & (6.68) \\
\hline \multirow{3}{*}{ Strong } & 1.76 & 1.55 & 1.64 & 1.79 & 1.76 & 1.78 & \multirow[b]{2}{*}{ Strong } & 1.71 & 1.95 & 1.77 & 1.81 & 1.80 & 1.37 \\
\hline & $(6.81)$ & (4.52) & $(5.40)$ & $(5.44)$ & $(5.35)$ & $(5.96)$ & & (8.28) & $(8.12)$ & $(8.03)$ & $(6.07)$ & $(7.97)$ & (5.87) \\
\hline & 0.62 & 0.59 & 0.26 & 0.69 & 0.87 & 0.70 & \multirow[b]{2}{*}{ SMW } & 0.24 & 0.73 & -0.67 & -0.05 & 0.37 & -0.21 \\
\hline SMW & $(4.92)$ & (3.54) & (1.01) & (3.81) & (5.19) & (3.02) & & $(1.56)$ & (4.03) & $(-2.25)$ & $(-0.21)$ & (1.61) & $(-0.77)$ \\
\hline
\end{tabular}

Second, after controlling for $\mathrm{ICL}$, on the left-hand side of Panel $\mathrm{A}$ in Table 3, the same equal-weighted strategy generates positive and significant returns four out of five $\mathrm{ICL}$ quintiles. In highly concentrated industry quintiles such as the $3^{\text {rd }}, 4^{\text {th }}$, and the $5^{\text {th }}$, SMW

8 SMW is named to differentiate from Fama and French's (2015) RMW factor, which is created based on operating profitability. 
strategy generates higher returns than the most competitive quintile. The highest average monthly return belongs to the $4^{\text {th }} \mathrm{ICL}$ quintile: $0.87 \%$ per month with a t-statistic of 5.19 . This equals $10.44 \%$ per year from 1973 to 2017 . However, when using value-weighted strategy, the only quintile that still generates positive returns with statistical significance is the most competitive quintile: $0.73 \%$ per month with a t-statistic of 4.03 . This supports my hypothesis. More importantly, the same SMW strategy in the $2^{\text {nd }} \mathrm{ICL}$ quintile produces a reversal return of $-0.67 \%$ per month with a t-statistic of -2.25 . Overall, out of the $25 \mathrm{ICL} \&$ GP/AT dependently sorted portfolios, the one with weakest GP/AT in the $2^{\text {nd }} \mathrm{ICL}$ quintile produces the highest monthly returns as $2.44 \%$ with a t-statistic of $6.67 \%$. It is $0.81 \%$ higher than the average monthly returns of the 25 portfolios. This group stands out so much that it drives the reversal SMW returns in the $2^{\text {nd }} \mathrm{ICL}$ quintile. It turns out that this group is consisted of 29 industries over time, but with Pharmaceutical and Oil companies taking up more than $65 \%$ of the positions. Displayed in Table 1, these two industries are at the bottom of $44 \mathrm{FF}$ industries in terms of average profitability. This suggests that gross profitability, may not be an efficient stock picking criterion when used to compare firms' performance across industries. The top 5 holding industries in this best performing portfolio are Pharmaceutical, Oil, Construction, Steel, and Business Services, together taking up $78.28 \%$ of the positions.

It is important to note that the market structure evolves over time. As mentioned earlier, the average industry concentration level declined sharply from 1973 to 1997 as more and more firms got listed on the three major exchanges. After 1997, the number of firms started to decline gradually, and $75 \%$ of industries become more and more concentrated over time. (Grullon et al., 2019). To test the robustness of SMW strategy over time, I split the sample into pre-1997 (industry expansion) and post-1997 (industry consolidation) period and calculate the equal weighted and value weighted returns. Results are presented in Table 4. Overall, the equal-weighted SMW strategies works consistently in both subsample periods, with the magnitude of returns slightly higher in industry expansion period. However, the $2^{\text {nd }} I C L$ quintile still does not produce any statistically significant returns. In industry consolidation period (1997-2017), both $2^{\text {nd }}$ and $5^{\text {th }}$ (highest concentration) ICL quintiles produce SMW returns indifferent from zero. It is safe to state that zero-investment strategies based on GP works well in competitive industries overall.

Likewise, the value weighted SMW strategy displays consistent return patterns with only the most competitive industry quintiles generating statistically significant returns. During the industry expansion period (1973-1997), SMW strategy generates $0.79 \%$ per month with a t-statistic of 2.95 only in the most competitive industry quintile. The reversal in $2^{\text {nd }} \mathrm{ICL}$ quintile appears to be significant only during the industry consolidation period (19972017). The opposite performance between the most and second-most competitive industry quintiles is the reason that when using all stocks, the value weighted SMW strategy generates returns that are indifferent from zero. Indeed, product market competition affects the performance of zero-investment strategy based on GP/AT, especially when using the value-weighted scheme.

Fama and French (2015) develop two new factors: RMW and CMA. RMW is based on operating profitability. Although it is different from gross profitability, I suspect that RMW may explain most of the value weighted SMW returns. To test this hypothesis, I perform time series of regression of the monthly SMW returns in each ICL quintile using the FF fourfactor (FF three-factor plus UMD ${ }^{9}$ ) and five-factor ${ }^{10}$ model. The risk-adjusted returns

\footnotetext{
9 UMD is the monthly premium of winners minus losers (Carhart, 1997).

10 Fama French factors are downloaded from Kenneth French's website:

https://mba.tuck.dartmouth.edu/pages/faculty/ken.french/data library.html
} 
(alphas) are presented in Table 5. The two models are displayed as equation (2) and (3) 11 below.

Table 4. Subsample Period Average Stock Returns of Portfolios by Gross Profitability, and by Gross Profitability \& Industry Concentration Level 19731996 and $1997-2017$

Note: This table presents the subsample period results of the zero-investment strategy based on gross profit to total assets ratio (GP) alone, and dependently sorted portfolios by industry concentration level (ICL) and GP/AT, same with Table 3. Portfolios are formed at the end of June in year $t$, and then held from July of year $t$ to June of year $t+1$. For portfolio formation, please refer to the detailed note for Table 3. Equal weighted raw returns (\%) are presented on the left-hand side; value-weighted raw returns (\%) are presented on the right-hand side. Tstatistics calculated from Newey-West adjusted standard errors are presented in parentheses.

\begin{tabular}{|c|c|c|c|c|c|c|c|c|c|c|c|c|c|}
\hline \multicolumn{14}{|c|}{ Panel A 1973-1996 } \\
\hline \multicolumn{7}{|c|}{ Equal Weighted Portfolio Returns } & \multicolumn{7}{|c|}{ Value Weighted Portfolio Returns } \\
\hline \multicolumn{7}{|c|}{ Industry Concentration level (FF48) } & \multicolumn{7}{|c|}{ Industry Concentration level (FF48) } \\
\hline GP & All & Low & 2 & 3 & 4 & High & GP & All & Low & 2 & 3 & 4 & High \\
\hline \multirow{2}{*}{ Weak } & 1.27 & 0.97 & 1.37 & 1.39 & 0.98 & 1.01 & \multirow{2}{*}{ Weak } & 1.56 & 1.33 & 1.84 & 2.07 & 1.6 & 1.76 \\
\hline & -4.01 & -3.58 & -3.13 & -3.12 & -2.29 & -2.88 & & -6.98 & -6.24 & -6.67 & -5.9 & -5.46 & -5.46 \\
\hline \multirow{2}{*}{2} & 1.25 & 1.22 & 1.09 & 1.4 & 1.12 & 1.13 & \multirow{2}{*}{2} & 1.49 & 1.48 & 1.53 & 1.84 & 1.68 & 1.37 \\
\hline & -5.01 & -4.1 & -3.51 & -4.6 & -3.72 & -3.72 & & -7.73 & -7.07 & -6.97 & -7.36 & -6.99 & -5.55 \\
\hline \multirow{2}{*}{3} & & & & & & 1.39 & \multirow{2}{*}{3} & & 1.67 & 1.45 & 1.68 & 1.53 & 1.62 \\
\hline & -5.73 & -4.42 & -4.15 & -4.68 & -4.3 & -4.36 & & -7.91 & -6.69 & -7.17 & -6.23 & -6.96 & -6.87 \\
\hline \multirow{2}{*}{4} & 1.54 & 1.42 & 1.48 & 1.45 & 1.36 & 1.58 & \multirow{2}{*}{4} & 1.57 & 1.67 & 1.68 & 1.52 & 1.49 & 1.63 \\
\hline & -6.09 & -4.49 & -5.31 & -4.59 & -4.43 & -5.26 & & -7.69 & -7.13 & -8.33 & -6.03 & -6.43 & -6.68 \\
\hline \multirow{2}{*}{ Strong } & 1.76 & 1.55 & 1.64 & 1.79 & 1.76 & 1.78 & \multirow{2}{*}{ Strong } & 1.71 & 1.95 & 1.77 & 1.81 & 1.8 & 1.37 \\
\hline & -6.81 & -4.52 & -5.4 & -5.44 & -5.35 & -5.96 & & -8.28 & -8.12 & -8.03 & -6.07 & -7.97 & -5.87 \\
\hline \multirow{2}{*}{ SMW } & 0.62 & 0.59 & 0.26 & 0.69 & 0.87 & 0.7 & \multirow{2}{*}{ SMW } & 0.24 & 0.73 & -0.67 & -0.05 & 0.37 & -0.21 \\
\hline & -4.92 & -3.54 & -1.01 & -3.81 & -5.19 & -3.02 & & -1.56 & -4.03 & $\begin{array}{r}(- \\
2.25) \\
\end{array}$ & $(-0.21)$ & -1.61 & $(-0.77)$ \\
\hline \multicolumn{14}{|c|}{ Panel B 1997 - 2017} \\
\hline \multicolumn{7}{|c|}{ Equal Weighted Portfolio Returns } & \multicolumn{7}{|c|}{ Value Weighted Portfolio Returns } \\
\hline \multicolumn{7}{|c|}{ Industry Concentration level (FF48) } & \multicolumn{7}{|c|}{ Industry Concentration level (FF48) } \\
\hline GP & All & Low & 2 & 3 & 4 & High & GP & All & Low & 2 & 3 & 4 & High \\
\hline \multirow{2}{*}{ Weak } & 0.99 & 0.95 & 1.39 & 0.77 & 0.78 & 1.15 & \multirow{2}{*}{ Weak } & 1.37 & 1.09 & 3.15 & 1.61 & 1.23 & 1.35 \\
\hline & $(2.17)$ & $(2.06)$ & $(1.84)$ & (1.34) & $(1.11)$ & $(1.80)$ & & $(3.76)$ & (3.93) & $(4.91)$ & $(2.91)$ & (3.02) & (3.20) \\
\hline \multirow{2}{*}{2} & 1.11 & 1.19 & 1.00 & 1.35 & 1.10 & 0.91 & \multirow{2}{*}{2} & 1.33 & 1.32 & 1.51 & 1.58 & 1.48 & 1.24 \\
\hline & $(2.93)$ & $(2.33)$ & (1.96) & $(2.98)$ & (2.09) & $(1.86)$ & & $(4.59)$ & (4.19) & $(4.06)$ & $(4.56)$ & $(4.09)$ & (3.35) \\
\hline 3 & 1.30 & 1.39 & 1.16 & 1.29 & 1.31 & 1.37 & 3 & 1.63 & 1.71 & 1.34 & 1.36 & 1.56 & 1.61 \\
\hline & $(3.65)$ & $(2.72)$ & $(2.56)$ & $(2.95)$ & (2.69) & $(2.82)$ & & $(4.70)$ & (3.87) & $(4.34)$ & $(3.41)$ & $(4.55)$ & (4.45) \\
\hline 4 & 1.37 & 1.41 & 1.54 & 1.20 & 1.24 & 1.58 & 4 & 1.49 & 1.81 & 1.55 & 1.38 & 1.36 & 1.29 \\
\hline & $(3.86)$ & $(2.75)$ & (3.62) & $(2.60)$ & $(2.74)$ & $(3.50)$ & & $(4.93)$ & (4.55) & $(5.73)$ & (3.74) & (3.83) & (3.55) \\
\hline st & 1.57 & 1.65 & 1.53 & 1.64 & 1.70 & 1.63 & & 1.61 & 1.75 & 1.68 & 1.81 & 1.56 & 0.94 \\
\hline & (4.29) & $(3.04)$ & (3.12) & $(3.44)$ & (3.35) & $(3.81)$ & & $(6.04)$ & (5.29) & (5.34) & $(4.46)$ & (4.98) & (3.91) \\
\hline & 0.58 & 0.70 & 0.14 & 0.87 & 0.92 & 0.49 & & 0.24 & 0.66 & -1.47 & 0.20 & 0.34 & -0.41 \\
\hline SMW & $(2.81)$ & (3.37) & $(0.33)$ & $(2.72)$ & (2.97) & (1.09) & SMW & $(1.12)$ & $(2.80)$ & $\begin{array}{r}(- \\
3.09)\end{array}$ & $(0.55)$ & $(0.91)$ & $(-1.10)$ \\
\hline
\end{tabular}

1 SMB (small minus big) is monthly premium of size factor; HML (high minus low) is the monthly premium of book to market factor; RMW (robust minus weak) is monthly premium of operating profitability factor; CMA (conservative minus aggressive) is monthly premium of investment factor. 


$$
\begin{gathered}
\operatorname{EXRET}_{t}^{12}{ }_{t}=\alpha+\beta_{1} \operatorname{EXMKT}_{t}+\beta_{2} S M B_{t}+\beta_{3} H M L_{t}+\beta_{4} U M D_{t}+\varepsilon_{t} \\
\operatorname{EXRET}_{t}=\alpha+\beta_{1} \operatorname{EXMKT}_{t}+\beta_{2} S M B_{t}+\beta_{3} H M L_{t}+\beta_{4} R M W_{t}+\beta_{5} C M A_{t}+\varepsilon_{t}
\end{gathered}
$$

\section{Table 5. Risk Adjusted Returns of SMW Strategies by Industry Concentration Level Quintile 1973-2017}

Note: This table presents the risk-adjusted monthly returns (\%) (alpha) of Strong Minus Weak (SMW) zeroinvestment strategies based on 25 industry concentration level (ICL) and gross profitability (GP) portfolios from 1973 to 2017, and two subsample periods. The alphas are calculated as the intercepts from time series regressions of SMW returns on Fama French four- and five-factor models. Equal weighted SMW alphas are presented on the left-hand side; value weighted SMW alphas are presented on the right-hand side. T-statistics

\begin{tabular}{|c|c|c|c|c|c|c|c|c|c|c|}
\hline & \multicolumn{5}{|c|}{ Equal Weighted SMW Portfolio } & \multicolumn{5}{|c|}{ Value Weighted SMW Portfolio } \\
\hline \multicolumn{11}{|c|}{ Panel A 1973-2017 } \\
\hline \multicolumn{6}{|c|}{ Industry Concentration Level } & \multicolumn{5}{|c|}{ Industry Concentration Level } \\
\hline & Low & 2 & 3 & 4 & High & Low & 2 & 3 & 4 & High \\
\hline \multirow{2}{*}{ FF4 } & 0.53 & 0.34 & 0.74 & 0.90 & 0.83 & 0.66 & -0.29 & 0.03 & 0.45 & 0.11 \\
\hline & $(4.10)$ & $(1.51)$ & $(4.71)$ & $(5.88)$ & (3.88) & $(3.57)$ & $(-1.11)$ & $(0.14)$ & (1.93) & $(0.47)$ \\
\hline \multirow{2}{*}{ FF5 } & 0.43 & 0.15 & 0.62 & 0.94 & 0.65 & 0.52 & -0.64 & -0.14 & 0.32 & 0.05 \\
\hline & (3.47) & (0.72) & (3.96) & (6.19) & (3.13) & $(2.84)$ & $(-2.68)$ & $(-0.61)$ & (1.37) & $(0.20)$ \\
\hline \multicolumn{11}{|c|}{ Panel B 1973-1996 } \\
\hline \multicolumn{6}{|c|}{ Industry Concentration Level } & \multicolumn{5}{|c|}{ Industry Concentration Level } \\
\hline & Low & 2 & 3 & 4 & High & Low & 2 & 3 & 4 & High \\
\hline FFA & 0.56 & 0.65 & 0.78 & 0.85 & 1.07 & 0.91 & 0.44 & 0.37 & 0.48 & 0.62 \\
\hline 124 & (3.16) & $(2.48)$ & $(4.21)$ & $(5.14)$ & $(4.67)$ & $(3.74)$ & $(1.35)$ & (1.37) & $(1.67)$ & $(2.00)$ \\
\hline 工 & 0.14 & 0.27 & 0.71 & 0.93 & 0.79 & 0.19 & -0.21 & 0.28 & 0.47 & 0.26 \\
\hline ris & (0.84) & $(1.01)$ & (3.70) & $(5.52)$ & $(3.40)$ & $(0.81)$ & $(-0.67)$ & $(0.98)$ & $(1.60)$ & $(0.81)$ \\
\hline \multicolumn{11}{|c|}{ Panel C 1997-2017 } \\
\hline \multicolumn{6}{|c|}{ Industry Concentration Level } & \multicolumn{5}{|c|}{ Industry Concentration Level } \\
\hline & Low & 2 & 3 & 4 & High & Low & 2 & 3 & 4 & High \\
\hline 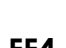 & 0.56 & 0.26 & 0.89 & 1.10 & 0.71 & 0.46 & -0.94 & 0.15 & 0.54 & -0.30 \\
\hline 254 & (3.08) & $(0.72)$ & $(3.48)$ & $(4.44)$ & $(1.94)$ & $(1.65)$ & $(-2.42)$ & $(0.43)$ & $(1.45)$ & $(-0.79)$ \\
\hline 55 & 0.55 & -0.03 & 0.67 & 1.15 & 0.53 & 0.37 & -1.36 & -0.05 & 0.35 & -0.48 \\
\hline dit & (2.95) & $(-0.08)$ & $(2.62)$ & $(4.36)$ & (1.43) & (1.32) & $(-3.70)$ & $(-0.13)$ & $(0.92)$ & $(-1.21)$ \\
\hline
\end{tabular}
of the alphas are in parentheses.

On the left-hand side of all three panels in Table 5, the FF five-factor model seems to be able to explain the SMW returns in most competitive industry quintile during industry expansion period (1973-1996) and the returns in the most concentrated industry quintile during industry consolidation period (1997-2017). All the other quintiles except the $2 \mathrm{nd}$ ICL quintile still displays strong positive risk-adjusted returns. This is expected because FF factors are created using value-weighted scheme. To my surprise, on the right-hand side in Table 5 panel A, it seems the FF five-factor model cannot explain the SMW returns in the most competitive quintile and the SMW reversals in the 2 nd ICL quintile. The FF fourfactor model seems to fully explain the SMW reversal returns in the 2nd ICL quintile.

12 EXRET stands for excess return, it is the stock/portfolio monthly return minus risk-free return.

13 EXMKT stands for excess market return. It is the market return minus risk-free return. 
However, as Panel $\mathrm{C}$ show, neither four- or five-factor model can explain the reversal returns during industry consolidation period (1997-2017).

In Panel B and C, the risk-adjusted returns of value-weighted SMW strategy from FF 5 factor model in the most competitive quintile is indifferent from zero, but the strong SMW reversal in the 2 nd ICL quintile has a staggering $-1.36 \%$ risk-adjusted return per month with a t-statistic of -3.70 . It is safe to say that, using value weighted strategy, the most profitable one is to long the firms with lowest GP/AT ratio and short the ones with highest GP/AT ratio at the end of June each year, and then hold such portfolio for 12 months before rebalancing in the 2 nd most competitive industry quintile. The evidence strongly suggests that product market competition level affects the performance of value-weighted zeroinvestment strategy based on gross profitability. While such strategy is profitable in the only most competitive industry quintile, a reversal strategy can generate much higher risk-adjusted returns in the 2 nd most competitive industry quintile.

\section{Conclusion}

Using publicly held firms from NYSE, AMEX, and NASDAQ from 1973 to 2017, I find that product market competition level affects the performance of the zero-investment strategy based on firm's gross profitability. While the strategy with an equally weighted scheme produces positive and significant returns in four out of five industry concentration level quintiles, the value-weighted strategy appears to be profitable only in the most competitive industry quintile. The evidence seems to support one of Sir John Templeton's stock picking criteria, by which firms that have higher profitability than their direct competitors tend to have higher future stock returns.

The difference between the results using two weighting schemes suggests that small firms are driving the results. More importantly, in the $2^{\text {nd }}$ most competitive industry quintile, the same value-weighted SMW strategy generates an astonishing risk-adjusted reversal return of $-0.64 \%$ per month from 1973 to 2017 , and an even stronger return of $-1.36 \%$ per month during the past two decades (industry consolidation period: 1997-2017). This reversal return is driven by the top performing portfolio from the $25 \mathrm{ICL}$ \& GP/AT dependently sorted ones. I find that more than $65 \%$ of this portfolio consists of two industries (Pharmaceutical and Oil) at the bottom of gross profitability compared to other non-financial Fama French industries.

What is more valuable from these findings is that while using gross profitability as stock picking criteria is reasonable, investors should caution when comparing firms across industries with different natures of business and different product market competition levels. When the industry becomes highly concentrated, where only one or a few firms dominate the market, profitability becomes much less effective in the zero-investment strategy.

\section{Acknowledgment}

I am grateful to an anonymous referee for very helpful comments on earlier versions of the paper. All remaining errors are my own. 


\section{References}

Ball, R., Gerakos, J., Linnainmaa, J., Nikolaev, V., 2015. Deflating profitability. Journal of Financial Economics 117 (2), 225-248.

Ball, R., Gerakos, J., Linnainmaa, J., Nikolaev, V., 2016. Accruals, cash flows, and operating profitability in the cross section of stock returns. Journal of Financial Economics $121,225-248$.

Carhart, Mark M., 1997, On Persistence in Mutual Fund Performance, Journal of Finance $52,57-82$.

Cohen, R., Polk, C., Vuolteenaho, T., 2003. The value spread. Journal of Finance 58 (2), 609-641

Fama, Eugene F., and Kenneth R. French, 1992, The cross-section of expected stock returns, Journal of Finance 47, 427-465.

Fama, Eugene F., and Kenneth R. French, 1993, Common risk factors in the returns of bonds and stocks, Journal of Financial Economics 33, 3-56.

Fama, Eugene F., and Kenneth R. French, 1997, Industry costs of equity, Journal of Financial Economics 43, 153-193.

Fama, Eugene F., and Kenneth R. French, 2008, Dissecting Anomalies, Journal of Finance 63, 1653-1678.

Fama, Eugene F. and Kenneth R. French, 2015, A five-factor asset pricing model, Journal of Financial Economics, 1 16, 1-22.

Grullon, G., Y. Larkin, and R. Michaely, 2019, Are US industries becoming more concentrated? Review of Finance, 1-47.

Haugen, Robert A., and Nardin L. Baker, 1996, Commonality in the determinants of expected stock returns, Journal of Financial Economics 41, 401-439.

Hou, K. and D. Robinson, 2006, Industry concentration and average stock returns, Journal of Finance 10: 1927-1956.

Kahle, K. M. and R. A. Walking, 1996, The impact of industry classifications and financial research, Journal of Financial and Quantitative Analysis 31, 309-335.

Newey, W., and K. West, 1987, A simple, positive semi-definite, heteroskedasticity and autocorrelation consistent covariance matrix, Econometrica 55, 703-708.

Novy-Marx, Robert, 2013, The other side of value: The gross profitability premium, Journal of Financial Economics 108, 1-28.

Schumpeter, J., 1912, The Theory of Economic Development (Harvard University Press, Cambridge, Mass). 